\title{
Virtual and Augmented Reality Applications in Landscape Design and Project Presentation Techniques ${ }^{\#}$
}

\author{
Orhun Soydan", , Ahmet Benliay ${ }^{2, b, *}$ \\ ${ }^{I}$ Faculty of Architecture, Landscape Architecture Department, Niğde Ömer Halisdemir University, 51240 Niğde, Turkey \\ ${ }^{2}$ Faculty of Architecture, Landscape Architecture Department, Akdeniz University, 07070 Antalya, Turkey
}

${ }^{*}$ Corresponding author

\begin{tabular}{l|l}
$\begin{array}{l}\text { A R T I C L E I N F O } \\
\text { "This study was presented as an oral } \\
\text { presentation at the 5th International } \\
\text { Anatolian Agriculture, Food, } \\
\text { Environment and Biology Congress } \\
\text { (Tokat, TARGID 2020) }\end{array}$ & $\begin{array}{l}\text { After realizing that multi-storey buildings are contrary to human nature, the importance of natural } \\
\text { landscape and green areas around it has been noticed. For this reason, people want to see how their } \\
\text { environment will be in the design phase and the importance of project presentations is increasing } \\
\text { day by day. Information technologies for spatial thinking, imagination and modelling have } \\
\text { gradually started to be included in landscape design processes. The concept of virtual reality, } \\
\text { augmented reality and immersive virtual reality are becoming more and more involved in our lives } \\
\text { due to reasons such as the size of the devices getting smaller and their prices being relatively } \\
\text { accessible to everyone. As an alternative to traditional presentation techniques and two-dimensional } \\
\text { presentation techniques on the computer, making presentations in a virtual reality environment can } \\
\text { be a stronger factor in people's perception of the environment. In the study visual sets in basic, } \\
\text { intermediate and advanced level of detail for the same landscape design and project site have been } \\
\text { created. Each set consists of hand-drawn perspective image, computer aided perspective image, } \\
\text { stereoscopic 360-degree VR image and an augmented reality model. In order to evaluate these } \\
\text { visual sets, interviews were made with 10 landscape architects who are experts in the subject. As a } \\
\text { result of the study, criteria's for landscape presentations has been discussed and the advantages and } \\
\text { disadvantages of landscape design presentations that will be created using virtual and augmented } \\
\text { reality have been evaluated. }\end{array}$ \\
$\begin{array}{l}\text { Received : } 25 / 09 / 2020 \\
\text { Accepted : } 02 / 11 / 2020\end{array}$ & $\begin{array}{l}\text { Keywords: } \\
\text { Presentation techniques } \\
\text { Virtual reality } \\
\text { Augmented reality }\end{array}$
\end{tabular}

Landscape design

Visual analysis

orhunsoydan@ohu.edu.tr (iD) https://orcid.org/0000-0003-0723-921X

|'@benliay@akdeniz.edu.tr

https://orcid.org/0000-0002-0902-2658

(c) (1) (9) This work is licensed under Creative Commons Attribution 4.0 International License

\section{Introduction}

Rapid urbanization and narrowing of living spaces increase the importance people give to the environment in which they live and in which they will live. For this reason, individuals want to see the environment in the design phase as landscape designs merge. For this reason, the importance of project presentations is increasing day by day.

Since the existence of the landscape architecture profession, 2D perspective images are used to present the imagined 3D ideas in landscape designs (Figure 1). With the help of technological possibilities, today's designer, who does not want to limit his designs, wants to establish a one-to-one relationship by defining all physical properties before realizing his project. Three-dimensional (3D) images of the landscape produced by computer graphics have been mainly used in landscape design presentations to predict the impact of the proposed design on the landscape. Today, there are many software that can be used for 3D modelling and visualization. With these software, it is possible to create impressive images in a short time (Figure 2). While speed and high-quality rendering are essential for many landscape architects and designers, portability can also be an important point that's often overlooked. With GPU technology getting more powerful while fitting into smaller form factors, it's become easier and more affordable to get a laptop with a powerful enough graphics card for optimal performance (Daniel 2018). Virtual reality, which is defined as an artificial environment where a user feels that it is a real situation, is considered as one of the important advances in landscape visualization. 


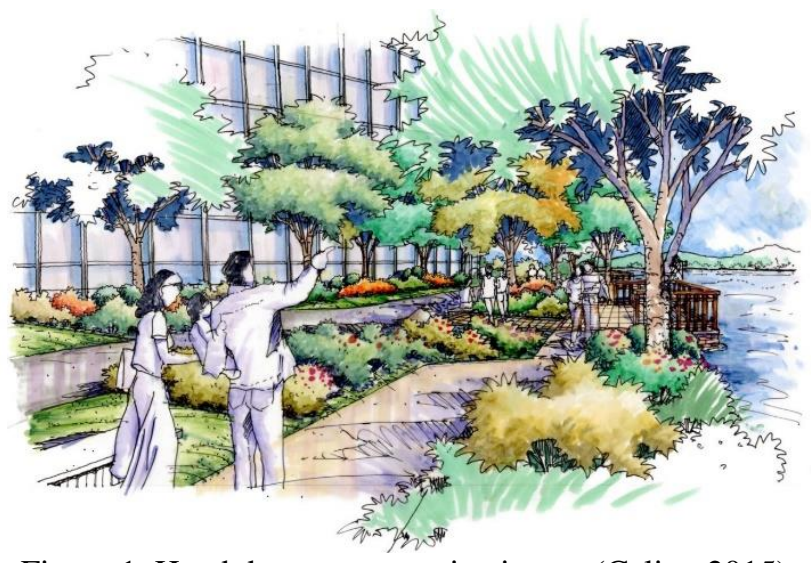

Figure 1. Hand drawn perspective image (Caling 2015)

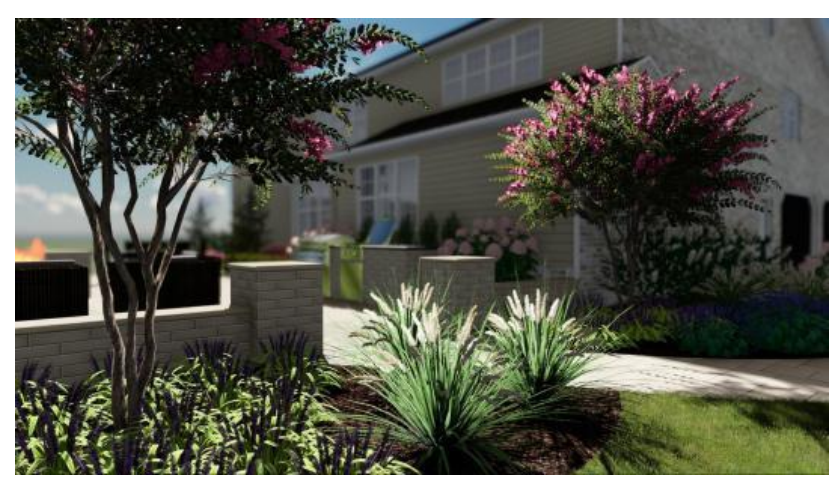

Figure 2. Computer aided 3D image (Daniel 2018)

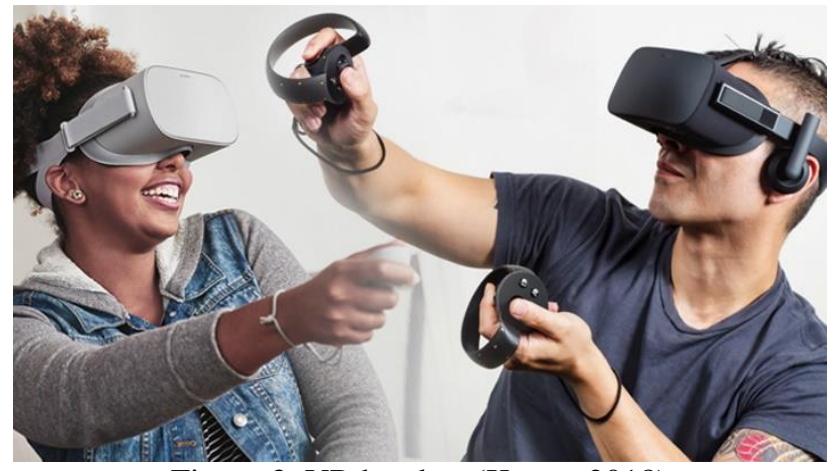

Figure 3. VR headset (Knapp 2018)

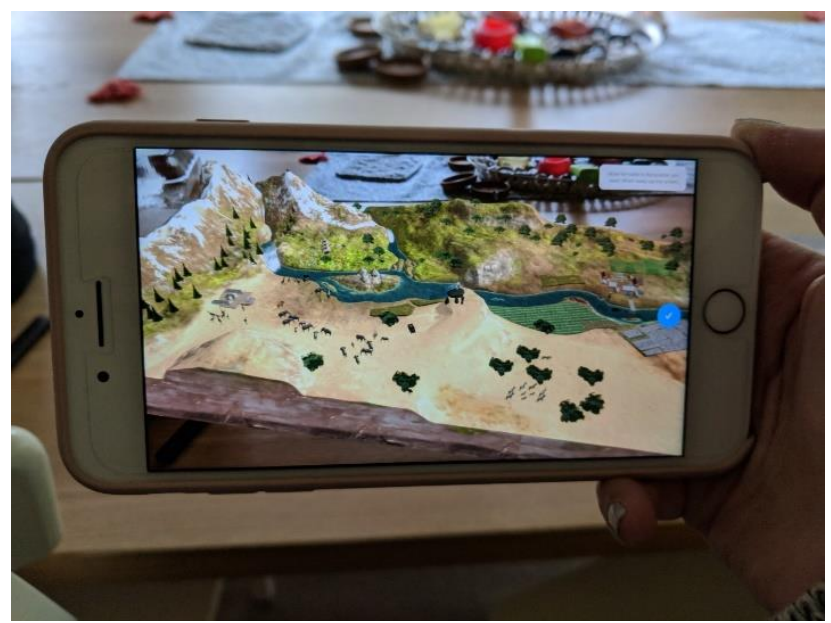

Figure 4.Using mobile phones for augmented reality (Stolyar 2020)
Virtual reality (VR) has become a mainstream term for referring to the creation and manipulation of a virtual world within a computer environment. With recent advances in computer technology, virtual reality images can be produced on a personal computer and it is possible to use virtual reality images as a medium for landscape assessment (Lim et al. 2006; Eve 2012). Nowadays, headsets that use computers or mobile devices as interfaces can be used to view VR images (Figure 3). Despite a lot of confusion, the concepts of virtual reality vs augmented reality are different from each other. Virtual Reality Systems were developed to simulate reality, by this users of virtual reality systems leave reality to browse an alternative reality generated by a computer system. Augmented Reality Systems blend together elements of reality with electronic elements generated by a computer system. Users can thus see real elements enriched with electronic information (Bimber O. and Rakar R. 2005; Kim G 2005; Cawood S. and Fiala M. 2008; Lopez et al. 2010).

Augmented Reality provide a timely way to combine the strengths of a computer-based approach (reproducibility, experimentation, computer reconstruction) with landscape. The addition of augmented reality to landscape designs means we are able to weave new experiences using any kind of virtual object (building reconstructions, vegetation, artwork, stone circles) but embed them firmly (and seamlessly) within the real world, share them with other users in our augmented world and refine them enough to be able to undertake real landscape designs into the design site in question (Eve 2012). Within the scope of this study, it is aimed to compare 4 presentation techniques. Their definition and competence have been tested among themselves.

\section{Material and Method}

In order to determine the advantages and disadvantages of landscape design presentations to be created using virtual and augmented reality, 3 sets of visuals for the same landscape design and project site were created. In order to make a variance in visual sets, they were created with different level of detail as basic, intermediate and advanced in drawing and modelling. Each of visual set includes 4 presentation techniques as hand-drawn perspective image (PT1), computer aided perspective image (PT2), stereoscopic 360-degree image can be viewed with the use of VR glasses (PT3), and augmented reality model viewable with the use of a mobile phone with AR capabilities (PT4). (Figure 4).

Sketch-up software was used for computer modelling and Lumion 10 software was used for creating CGI and stereoscopic 360-degree images. Stereoscopic 360-degree images presented by the use of Samsung Gear VR and augmented reality model has been presented by the use of Arloopa app.

In this study, face-to-face interviews were conducted with 10 landscape designers who are experts in landscape design visualization. First of all, experts were asked what the criteria should be in the landscape design presentation before the visual sets prepared for the study were shared. The evaluation criteria were selected as Competence, Noticeability, Effectiveness, Legibility, Realism, Spatial Referencing and Reliability by the experts. 
After this, presentation techniques in each visual sets were evaluated by experts on a 5-point Likert scale as relationship level with the lowest value of 1 and highest value of 5. Erzurumlu and Kahveci (2017), used a similar method in their study, and they grouped the users and tried to determine their opinions in terms of visual analysis.

Before evaluation all presentations of visual sets have been shown to experts so that they can distinguish their aspects from each other more clearly. The mean and standard deviation values of these expert opinion evaluations were calculated and the advantages and disadvantages of presentation technology are discussed on the basis of determined criteria by the level of detail.

\section{Results and Discussion}

Computer aided presentation techniques, which increased in parallel with the developments in technology, started to replace traditional presentation methods rapidly. Nevertheless, hand-made perspective images can still be preferred due to their abstract expression, warm structure and artistic power. In addition to architectural foresight, intensive training and skill are also needed for the expecting in hand-made perspective images. But with the features they provide, computer-generated presentation techniques help to create high quality visuals with less training and skills. Regardless of which technique is used, the presentation should impact the viewer, depict the space, be coherent and convey the spirit of the design.

The evaluation criteria determined during the study include hints about what should be considered while preparing a presentation for landscape design. Expert group agreed that a presentation for landscape design should include seven main headings. But they point out that the criteria may differ depending on the structure, nature and purpose of the presentation. One of the most important facts determined in the oral interviews with experts is that these criteria can be changed and increased in numbers according to the content of the design to be carried out. In addition, these seven main keywords contain many data to be evaluated within themselves.
The average and standard deviation values of the evaluations made by the experts for presentations are given in Table 1. The average values differs between 1.8 to 4.6 in a range between 1 to 5 . The average of the scores given in the overall study was determined to be 3.632 . Considering that every value above the mean value of 3 in this study is considered to be positive, it can be evaluated that the experts have a positive approach to presentation techniques in terms of all criteria.

Lowest average value is PT1 in Basic detail for Spatial referencing criteria with 1.8. Also PT1 in Basic detail for Competence and PT1 in Intermediate detail for Spatial referencing have a value of 2.1 in average.

Highest average values are in PT3 in Intermediate detail in Competence, PT4 in Intermediate detail for Noticeability and PT4 in Advanced detail for Effectiveness criteria with 4.6.

In terms of the values given by the experts, the lowest standard deviation is PT2 in Advanced detail for Reliability with 0.316 standard deviation and an average of 4.1. Also PT2 in Intermediate detail for Competence has a value of 0,378 standard deviations and an average of 4.1 . These values can be considered as the experts gave much closer values according to other presentation techniques. Highest standard deviation is PT1 in Basic detail for Reliability criteria with 1.418 standard deviation and an average of 2.7. Also PT2 in Basic detail for Spatial referencing has a value of 1.337 standard deviation and an average of 3.,1. These values can be considered as the experts gave much distributed values according to other presentation techniques.

The average and standard deviation values of the presentation techniques in order to evaluate the presentation techniques by excluding the level of detail used are given in Table 2. With the help of the combined data, the level of detail used was excluded and the presentation techniques were evaluated within themselves. The lowest value in presentation techniques is PT1 for Spatial referencing criteria with 0.458 standard deviation and 2.2 average. The highest value in presentation techniques is PT3 for Realism with 0.404 standard deviation and 4.3 average.

Table 1. The average and standard deviation values of the expert evaluations

\begin{tabular}{|c|c|c|c|c|c|c|c|c|c|c|c|c|c|c|}
\hline & & \multicolumn{4}{|c|}{ Basic Detail } & \multicolumn{4}{|c|}{ Intermediate Detail } & \multicolumn{4}{|c|}{ Advanced Detail } & \multirow{2}{*}{$\begin{array}{l}\text { Criteria } \\
\text { Average }\end{array}$} \\
\hline & & PT1 & PT2 & PT3 & PT4 & PT1 & PT2 & PT3 & PT4 & PT1 & PT2 & PT3 & PT4 & \\
\hline \multirow{2}{*}{ Competence } & Mean & 2.1 & 3.0 & 3.5 & 3.6 & 2.8 & 4.1 & 4.6 & 4.5 & 3.3 & 4.3 & 4.5 & 4.6 & 3.658 \\
\hline & St. D & 1.197 & 0.994 & 0.527 & 0.699 & 1.033 & 0.378 & 0.699 & 0.707 & 0.823 & 0.738 & 0.422 & 0.483 & 0.757 \\
\hline \multirow{2}{*}{ Noticeability } & Mean & 2.9 & 3.5 & 3.5 & 3.4 & 3.0 & 4.1 & 4.0 & 4.6 & 2.9 & 3.8 & 3.9 & 4.4 & 3.667 \\
\hline & St. D & 0.994 & 0.925 & 1.287 & 0.707 & 1.054 & 0.690 & 0.667 & 0.516 & 0.876 & 0.919 & 1.101 & 0.699 & 0.566 \\
\hline \multirow{2}{*}{ Effectiveness } & Mean & 2.3 & 3.2 & 3.5 & 3.5 & 3.5 & 3.9 & 4.0 & 4.3 & 3.1 & 4.1 & 4.1 & 4.6 & 3.675 \\
\hline & St. D & 1.160 & 0.888 & 0.630 & 0.707 & 1.080 & 1.197 & 0.820 & 0.480 & 0.738 & 0.568 & 0.740 & 0.520 & 0.625 \\
\hline \multirow{2}{*}{ Legibility } & Mean & 2.4 & 3.1 & 3.3 & 3.3 & 2.6 & 4.0 & 4.5 & 4.2 & 2.7 & 3.8 & 4.3 & 4.3 & 3.542 \\
\hline & St. D & 1.075 & 1.056 & 0.700 & 0.520 & 0.843 & 0.816 & 0.710 & 0.422 & 0.699 & 0.789 & 0.949 & 0.483 & 0.738 \\
\hline \multirow{2}{*}{ Realism } & Mean & 2.7 & 3.3 & 3.8 & 3.7 & 2.9 & 4.2 & 4.5 & 4.3 & 2.4 & 4.0 & 4.5 & 4.4 & 3.725 \\
\hline & St. D & 1.059 & 0.919 & 0.520 & 0.699 & 0.568 & 0.632 & 0.710 & 0.483 & 0.516 & 0.471 & 0.850 & 0.843 & 0.736 \\
\hline \multirow{2}{*}{$\begin{array}{l}\text { Spatial } \\
\text { Referencing }\end{array}$} & Mean & 1.8 & 3.1 & 3.8 & 3.9 & 2.1 & 3.9 & 4.1 & 4.1 & 2.7 & 4.0 & 4.0 & 4.1 & 3.467 \\
\hline & St. D & 0.919 & 1.337 & 1.054 & 0.471 & 0.876 & 0.738 & 0.994 & 0.568 & 0.675 & 0.667 & 0.667 & 0.738 & 0.833 \\
\hline \multirow{2}{*}{ Reliability } & Mean & 2.7 & 2.9 & 3.3 & 3.8 & 2.9 & 4.4 & 4.5 & 4.3 & 3.0 & 4.1 & 4.2 & 4.2 & 3.692 \\
\hline & St. D & 1.418 & 0.949 & 0.480 & 0.568 & 0.738 & 0.516 & 0.707 & 0.483 & 0.667 & 0.316 & 0.789 & 0.422 & 0.680 \\
\hline \multirow{2}{*}{ Total } & Mean & 2.4 & 3.2 & 3.5 & 3.6 & 2.8 & 4.1 & 4.3 & 4.3 & 2.9 & 4.0 & 4.2 & 4.3 & 3.632 \\
\hline & St. D & 0.385 & 0.199 & 0.206 & 0.216 & 0.423 & 0.177 & 0.267 & 0.170 & 0.298 & 0.127 & 0.198 & 0.160 & 0.673 \\
\hline
\end{tabular}


Table 2. The average and standard deviation values of the presentation techniques

\begin{tabular}{ll|ccccc}
\hline \multirow{2}{*}{ Competence } & & \multicolumn{3}{c}{ Average of Detail Levels } & \multicolumn{2}{c}{ Criteria } \\
& & Average \\
\cline { 2 - 6 } & Mean & 2.7 & 3.7 & 4.1 & 4.1 & 3.950 \\
\multirow{2}{*}{ Noticeability } & St. D & 0.603 & 0.586 & 0.557 & 0.473 & 0.585 \\
& Mean & 2.9 & 3.8 & 3.8 & 4.1 & 3.858 \\
\multirow{2}{*}{ Effectiveness } & St. D & 0.058 & 0.300 & 0.265 & 0.643 & 0.605 \\
\hline \multirow{2}{*}{ Legibility } & Mean & 3.0 & 3.7 & 3.9 & 4.1 & 3.958 \\
& St. D & 0.611 & 0.473 & 0.321 & 0.569 & 0.448 \\
\hline \multirow{2}{*}{ Realism } & Mean & 2.6 & 3.6 & 4.0 & 3.9 & 3.855 \\
& St. D & 0.153 & 0.473 & 0.643 & 0.551 & 0.824 \\
\hline \multirow{2}{*}{ Spatial Referencing } & Mean & 2.7 & 3.8 & 4.3 & 4.1 & 3.925 \\
& St. D & 0.252 & 0.473 & 0.404 & 0.379 & 0.783 \\
\hline \multirow{2}{*}{ Reliability } & Mean & 2.2 & 3.7 & 4.0 & 4.0 & 3.542 \\
& St. D & 0.458 & 0.493 & 0.153 & 0.115 & 0.839 \\
\hline \multirow{2}{*}{ Total } & Mean & 2.9 & 3.8 & 4.0 & 4.1 & 3.967 \\
& St. D & 0.153 & 0.794 & 0.624 & 0.265 & 0.561 \\
\hline
\end{tabular}

It has been determined that hand drawn perspectives presented in various details are below the average success level in terms of today's presentation technique standards. Results shows that experts agree on computer-aided presentation techniques can produce much more effective results. Even the non-stereoscopic render images have an average of 3.7 and virtual reality and augmented reality presentation techniques average values are more than 4.0. The average values of basic, intermediate, and advanced detail visual sets were $3.2,3.9$, and 3.8, respectively.

Although there is no significant difference in the intermediate and advanced level of detail in the evaluation of expert opinion, it is seen that the average value has decreased at the simple detail level. Likewise, it is seen that the standard deviation values also increase in the level of simple detail. The lower values of the simple detailed data set were as predicted at the beginning of the study. However, as the level of detail increased, there was smaller increase in average values. This can be interpreted as the success of the presentation is more related to the technique rather than the detail level.

\section{Conclusion}

The experience gathered examined the absence of a general scene perception arrangement. Normally it involves choosing the most appropriate procedure for a particular job and assisting with such decisions. In general, there is an undeniable edge between the detail and originality that can be imagined with the delivered pictures, and the clever abilities of continuous models, such as looking at screens with mid-positions or vividness. 3D visualization tools will not be applicable to all landscape design studies, and the desired results may not be achieved with modelling inefficiently or with insufficient details. The use of complementary abstract and realistic visualizations which are created by the appropriate design process and whose purpose, spatial integrity and effect has been determined beforehand, will increase the benefits to be obtained from the presentations. Whatever the actual techniques used to produce visualizations, one point that needs to be re-emphasized is the importance of ensuring the credibility and legitimacy of representations for the target audience. Virtual and Augmented Reality presentations have many advantages over traditional presentation techniques. These are;

- Increasing the perceptibility of spatial references due to the possibility of movement in presentation.

- Being realistic and impressive due to the fact that it allows the stereoscopic view like the eye's own structure.

- More legible, because they allow to zoom in and out within the presentation and the user can see the details more clearly.

- More competence and effective due to allowing the use of the latest technical advantages and equipment.

However, these presentation techniques also have various disadvantages. Such as;

- It requires expensive hardware as a system. Especially VR glasses and hardware that AR systems can work are still expensive today.

- Presentations take longer to create. Also need a powerful computer system is needed.

- Technical information is required for the preparation of images. Especially in AR systems, the spatial description of the images is required.

- $\quad$ Some users find it difficult to operate.

It should not be forgotten that the adoption of each new technology takes place in a certain period. It is very likely that new presentation techniques will emerge in the near future with many innovations in communication technologies. The important thing is not what technique to use, but what kind of benefits it will provide us in the presentation of landscape designs. Also it is important for landscape designers to balance the impulse to apply the latest technology with a more comprehensive and critical assessment of how they are used and what are the benefits it can bring.

\section{References}

Bimber O, Rakar R. 2005. Spatial Augmented Reality. Merging Real and Virtual Worlds. A. K. Peters, Ltd. 
Caling R. 2015. Landscape Hand Drawn Perspectives. COROFLOT. Available from: https://www.coroflot.com/ ARKIRON/Landscape-Hand-Drawn-Perspectives [Accessed 28 August 2020]

Cawood S, Fiala M. 2008. Augmented Reality: A practical guide. Pragmatic Bookshelf.

Daniel M. 2018. The Power of Lumion for Small Landscape Architecture and Design Firms. Lumion. Available from: https://lumion.com/blog/the-power-of-lumion-for-smalllandscape.html [Accessed 28 August 2020]

Erzurumlu GS, Kahveci B. 2017. The Assessment of Nigde Omer Halisdemir Campus with Regards to Landscape Quality. Scholars Bulletin, 3(12): 718-726., Doi: 10.21276/ sb.2017.3.12.13

Eve S. 2012. Augmenting Phenomenology: Using Augmented Reality to Aid Archaeological Phenomenology in the Landscape. J Archaeol Method Theory (2012) 19: 582-600. DOI: $10.1007 / \mathrm{s} 10816-012-9142-7$
Knapp M. 2018. Oculus Go vs Oculus Rift: should you switch to the standalone VR headset? Techradar. Available from: https://www.techradar.com/news/oculus-go-vs-oculus-rift [Accessed 28 August 2020]

Kim G. 2005. Designing Virtual Reality Systems: The Structured Approach. Springer, 2005.

Lim EM, Hondo T, Umeki K. 2006. The validity of VRML images as a stimulus for landscape assessment Landscape and Urban Planning 77(2006): 80-93.

López H, Navarro A, Relaño J. 2010. An Analysis of Augmented Reality Systems. 2010 Fifth International Multi-conference on Computing in the Global Information Technology. ICCGI 2010. September 20-25, 2010 - Valencia, Spain.

Stolyar B. 2018. WWF Free Rivers App Puts a Virtual Landscape on Any Flat Surface. Digitaltrend. Available from: https://www.digitaltrends.com/mobile/app-attack-wwf-freerivers/ [Accessed 28 August 2020] 